\title{
On the Hyperglycemia in Man, Produced by Duodenal Introduction of Glucose
}

By

\section{Ichiro Uyeda}

(植田一郎)

(From the Medical Clinic of Prof. T. Kurokawa,

Tohoku University, Sendai)

(Received for publication, August 29, 1952)

Variations in the sugar content in the general blood on the introduction of glucose into the duodenum by means of a duodenal tube will be illustrated in the following paragraphs.

The test was done in healthy persons, i.e. those without any disturbances rê the carbohydrate tolerance. In fact this was carried out as the control of the double administration experiments; previously reported. ${ }^{11}$

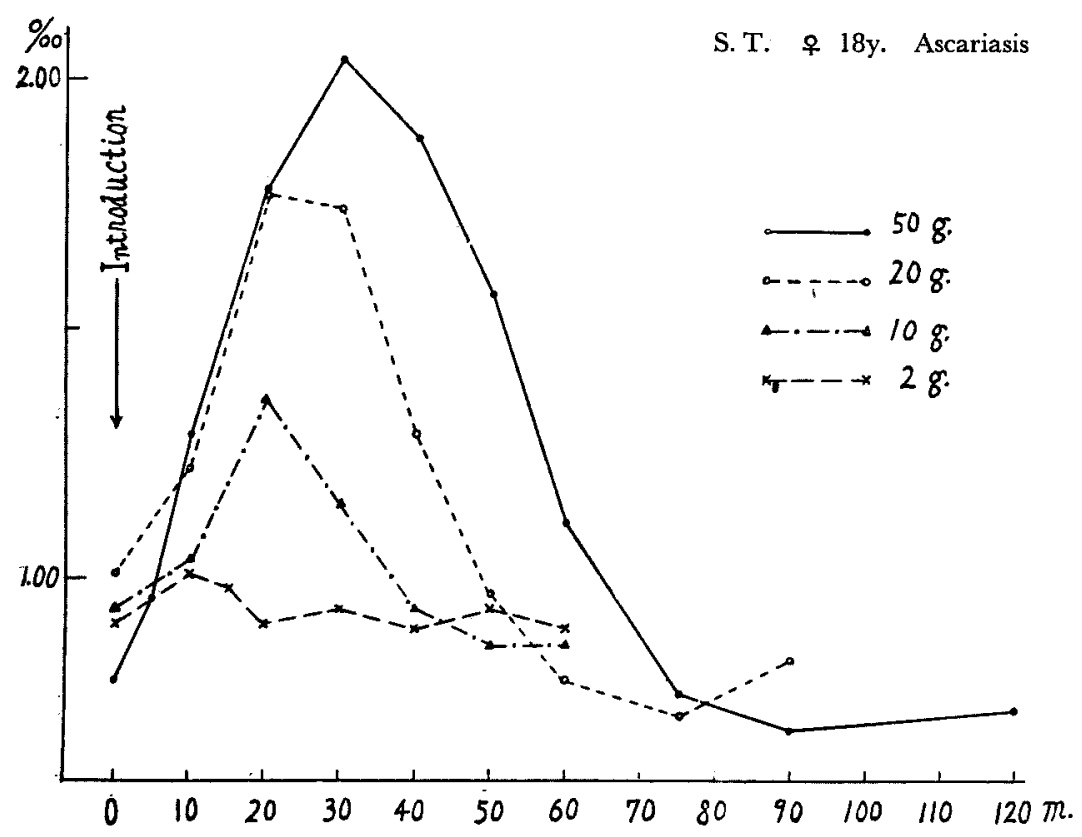

Introduction into duodenum of glucose in various doses 
The routine diet consists of $440 \mathrm{~g}$. carbohydrate, $90 \mathrm{~g}$. protein and $40 \mathrm{~g}$. fat, and involves about 2500 Calories. In the early morning after the night fast a certain amount of glucose, solved in $100 \mathrm{cc}$. distilled water and warmed at $37^{\circ}$, was introduced into the duodenum by means of the tube. 2-50 g. were given to 18 individuals.

In general the general blood sugar sets in to incerase two minutes after introduction. $10 \mathrm{~g}$. glucose are enough to see a definite increase in the sugar concentration; the greater the dose, the greater the hyperglycemia and the faster the increase. And when $20 \mathrm{~g}$. glucose is administered the rapidity with which the sugar concentration increases, reaches the maximum, that is the ascending limb of hyperglycemia there wholly coincides with that on $50 \mathrm{~g}$. glucose. The peak of hyperglycemia is however higher in the case of $50 \mathrm{~g}$. glucose than that of $20 \mathrm{~g}$. glucose.

And the duration of hyperglycemia depends also to the doses, and when the dose large enough the hypoglycemia develops finally; the larger the dose, the larger the hypoglycemia.

1

In short: The blood sugar fluctuations in healthy persons due to the direct administration of glucose into the duodehum are figured according to doses.

\section{References}

1) Uyeda, Tohoku J. Exp. Med., 1952, 55, 195. 